\title{
Training for team-based care: Development of a continuing education curriculum for General Practice pharmacists in Australia
}

\author{
Helen Benson (iD, Cherie Lucas, Jim Woulfe \& Kylie A Williams \\ Graduate School of Health, The University of Technology Sydney, Australia
}

\section{Keywords}

Advanced Practice

Lifelong Learning

Postgraduate Education

\section{Correspondence}

Dr Helen Benson

University of Technology Sydney

Graduate School of Health Level 6

100 Broadway Ultimo

NSW 2007

Australia

helen.benson@uts.edu.au

\begin{abstract}
Background: The integration of pharmacists into primary care and general practice teams is expanding. Equipping pharmacists with the skills and knowledge to perform as part of a primary care team will facilitate this expanded scope of practice. Aim: This paper describes the rationale and approach for the development of a competency aligned curriculum of a postgraduate pharmacist education programme in Australia. Methods: The authors describe an evidence-based approach to curriculum development including establishing an educational programme advisory committee, consultation with an expert panel of pharmacy practice educators, and mapping of curriculum to both learning outcomes and competency standards. Conclusions: The curriculum design approach ensures the programme is designed to provide pharmacists with the skills, training and knowledge required to perform the General Practice pharmacist role. The education programme is due to be piloted in 2020 , followed by an evaluation to allow further adjustment and improvement of the course design.
\end{abstract}

\section{Introduction}

Two recent systematic reviews (Tan et al., 2014; Hazen et al., 2018) have highlighted the impact of General Practice (GP) pharmacists in chronic disease management and patient-centred care. GP pharmacists are required to perform a wide range of professional activities, and require additional post-registration training to gain the skills and knowledge required to perform these roles (Anderson et al., 2018; Benson et al., 2018b).

The WentWest General Practice Pharmacist Project was commissioned by the Western Sydney Primary Health Network to trial the implementation of a patient-centred primary care model of including a pharmacist as part of the general practice team. This project involved the integration of pharmacists across multiple general practice sites in Western Sydney. The project commenced in March 2016 and is ongoing. An evaluation of the project identified that a lack of specific GP pharmacist training as a significant barrier to the intervention's success (Benson et al., 2018a; Benson et al., 2018b).

In response to this evidence, and due to the increasing number of pharmacists practicing in general practice settings in Australia, it was deemed by the local area health service that the development of an explicit curriculum directed at providing GP pharmacists with the skills, training and knowledge to perform the role was required. 
The involvement of pharmacists as part of primary care or general practice teams is increasing, but few education programmes address the exact needs of GP pharmacists. Specific GP pharmacist education programmes have been developed in the United Kingdom (UK) and the Netherlands, and more general primary care pharmacist education is available in the United States of America (USA) and Canada (Butterworth et al., 2017; Moczygemba et al., 2017; Hazen et al., 2018).

\section{Description of course}

In response to a specific need identified by an Australian local area health service, academics from the Graduate School of Health (GSH) Discipline of Pharmacy were appointed to develop and deliver a postgraduate continuing education programme for GP pharmacists. It was decided to follow the GSH's established learning design process (Figure 1), incorporating industry consultation (which in this case involved consulting with the Western Sydney Primary Health Network [PHN] GP Pharmacist Educational Programme Advisory Committee), collaborative development of learning objectives, alignment with industry competency standards, and comprehensive feedback and evaluation processes. Aligned with the Australian Qualifications Framework (Australian Qualifications Framework Council, 2013) at the postgraduate level, the course is a Graduate Certificate in Advanced Practice (General Practice Pharmacist), a formal qualification enabling licensed pharmacists to develop the skills and knowledge required to carry out the role of a GP pharmacist.

The part-time programme, also delivered by the GSH, takes a minimum of 12 months to complete. The programme is designed for multi-modal delivery, integrating short on-campus residential components, online modules and clinical placement experiences.

Residential components consist of a maximum of two weeks per unit of study and enable the development of hands-on tasks such as screening and patient examination, and group-based activities such as communication methods training. The final residential component at the end of the communication, inter-professional collaboration and clinical placement subjects includes an Objective Structured Clinical Examination (OSCE), for the assessment of target competencies in 'live' case-based format.

In online modes, course units include ten one-hour online tutorials. Clinical placement experiences consist of a twoweek full-time placement (40 hours) or four hours of placement per week for ten weeks at a general practice site.

\section{Curriculum development}

In 2010, the Carnegie Foundation's Flexner centenary report related to the future of medical education in the USA (Cooke et al., 2010), endorsed a competency-based approach to curriculum development as a gold standard. Competency-based models are becoming the dominant method for evidence-based curriculum development in the health sciences (Iglar, Whitehead, \& Takahashi, 2013; Gruppen et al., 2016; Katajavuori et al., 2017; Lockyer et al., 2017). In line with this, the use of Competency Based Education ( $\mathrm{CBE}$ ) in pharmacy continuing education is becoming increasingly widespread. (Bruno et al., 2010; Farrell et al., 2012; Foot et al., 2017; Koster, Schalekamp, \& Meijerman, 2017).

CBE is closely linked to assessment, but the relationship to teaching and learning activities is less well established (Morcke, Dornan, \& Eika, 2013). According to Frank et al. CBE differs from traditional educational approaches as it focuses on outcomes and abilities of graduates, with a reduction in the emphasis on time-based training and promotes learner-centredness (Frank et al., 2010).

To take a learner-centred approach, Biggs and Tang (2011) propose constructive alignment in curriculum design is essential. A constructively aligned curriculum is described as one that envelops the learner in a system, where intended learning outcomes, teaching and learning activities, assessment tasks and their grading support each other (Biggs \& Tang, 2011). In addition, Boud and Falchicov (2006) emphasise the importance of designing assessments that facilitate learning and encourage prospective learning after completion of the training programme.

Figure 1: GSH Learning design process adapted for the Graduate Certificate in Advanced Practice (GP Pharmacist)

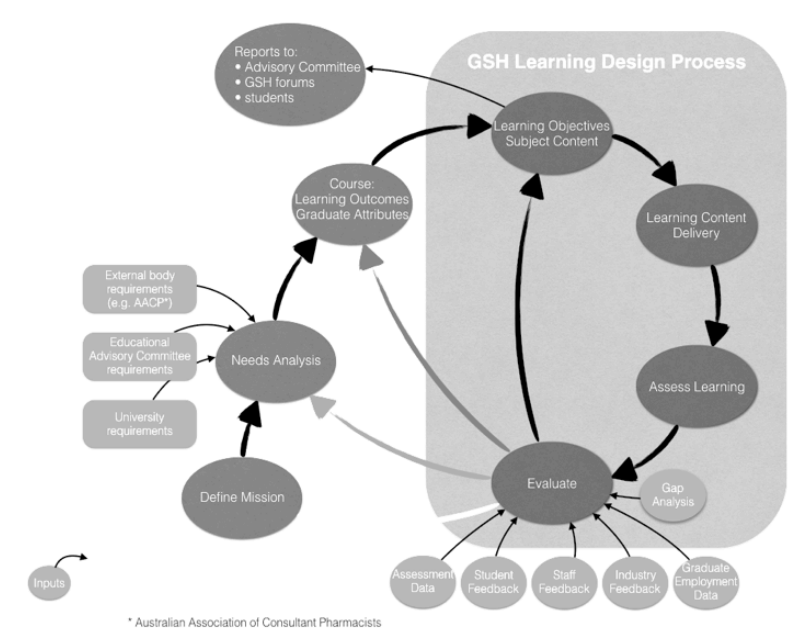




\section{Course construction}

Figure 1 shows the GSH learning design process. In the case of the Graduate Certificate in Advanced Practice (General Practice Pharmacist), the needs analysis phase included defining the GP pharmacist scope of practice by performing a comprehensive review of the international literature relating to the roles of GP pharmacists (Benson et al., 2019). A GP pharmacist competency map was developed by mapping the roles included in the scope of practice to the National Competency Standards Framework for Pharmacists in Australia (Pharmaceutical Society of Australia, 2016b).

The results of the literature review identified seven role sub-categories and 48 individual activities performed by GP pharmacists (Figure 2).

\section{Figure 2: GP Pharmacist roles}

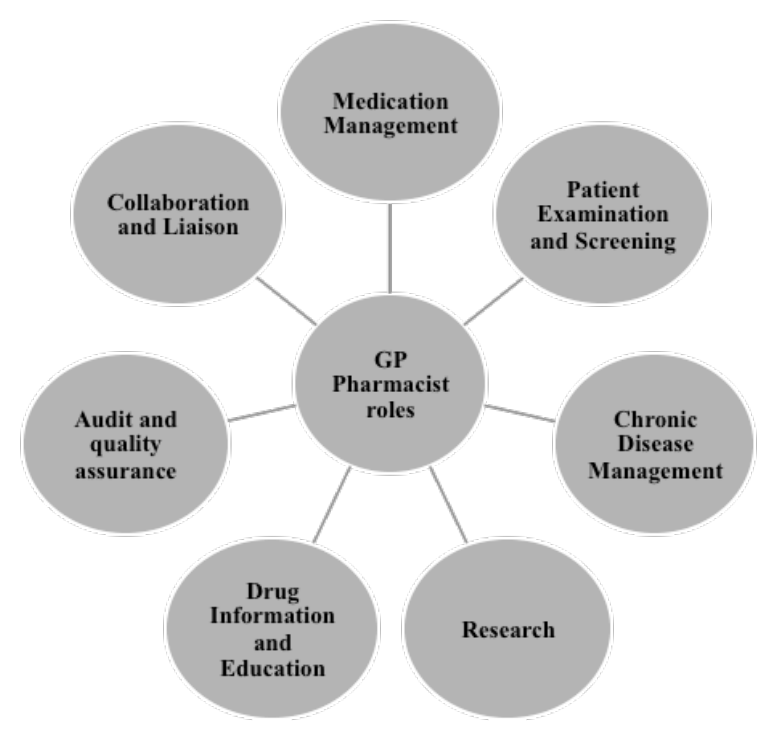

Examples of GP pharmacist activities from each role subcategory are outlined below:

1) Medication management activities included conducting comprehensive medication review and repeat prescribing

2) Patient examination and screening activities included conducting spirometry and the review and provision of immunisation

3) Chronic disease management activities included conducting group education for chronic disease and adjusting doses under a chronic disease treatment protocol
4) Research activities included participating in general practice research projects

5) Drug information and education activities included the provision of medication education to both prescribers and patients

6) Audit and quality and assurance activities included conducting drug use evaluations and audits of prescribing

7) Collaboration and liaison activities included transition of care management between hospital, community and aged care settings.

When designing the postgraduate course, the educational design team needed to differentiate between GP pharmacist activities that could be performed by newly registered pharmacists, and those that registered/licensed pharmacists would need additional training to gain the skills and knowledge to perform.

Both the GP pharmacist scope of practice and competency map were used to define proposed GP pharmacist educational needs. An expert panel of Australian pharmacy practice educators was consulted via a Delphi validation process to establish a consensus position on the educational needs of registered/licensed pharmacists wishing to perform the GP pharmacist role (Benson, Lucas \& Williams, 2020)

The Delphi validation process is a method used to establish an evidence-based consensus by providing a systematic method for collecting and aggregating informed judgements from a group of experts via multiple rounds of input (Mckenna, 1994). Feedback given following sequential rounds allows experts to be informed by the opinions of other panellists and to reassess their responses in light of this feedback. The Delphi method maximises the benefits of using an expert panel while allowing anonymity of response (Thangaratinam, 2005).

Pharmacy practice experts were approached from all Australian pharmacy schools and experts from 10 of a possible 18 pharmacy schools (56\%) participated as part of the panel. The study defined a proportion of experts rating agree or disagree at $\geq 75 \%$ to determine consensus and disagree or strongly disagree at $\geq 75 \%$ as nonconsensus. The expert panel reached consensus to agree that the GP pharmacist programme needed to provide training in all role sub-category areas and for $26 \mathrm{GP}$ pharmacist activities. Examples of GP pharmacist activities designated as educational needs included conducting comprehensive medication reviews, repeat prescribing, conducting focused physical examinations, and clinical 
prescribing audits. The panel deemed that some individual GP pharmacist activities such as taking a medication history, counselling on lifestyle modifications and providing medication device training did not need to be addressed by the programme as pharmacists would be capable of performing these roles at initial registration. The GP pharmacist educational needs, identified by the expert panel, were used to inform both the learning outcomes for the programme and the learning objectives for the Units of Study (UoS).

\section{Figure 3: Example of constructive alignment of educational needs, learning objectives, learning activities and assessment}

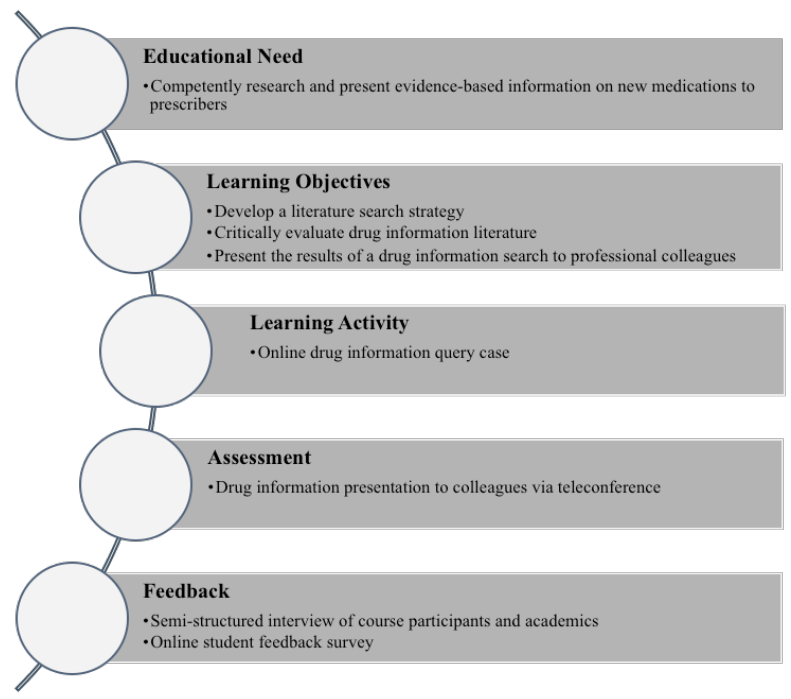

To address the GSH's established process of consulting relevant industry in educational design the GP Pharmacist Educational Programme Advisory Committee (consisting of a General Practitioner, three pharmacy practice experts, an educational designer and two representatives from the Western Sydney PHN) was consulted to confirm the validity of learning outcomes and objectives, learning activities, UoS outlines and curriculum design. Learning outcomes and objectives, learning activities and assessment tasks were aligned to support the learner in the development of professional competence.
Figure 3 shows an example of how identified educational needs were constructively aligned to learning objectives, learning activities and assessments. Four UoS have been developed to address the educational needs identified.

The four UoS include:

1) Medication management (for pharmacists not accredited to perform medication reviews) OR advanced medication management (for pharmacists who are accredited to perform medication review)

2) Inter-professional communication and collaboration

3) Evidence based practice

4) Clinical placement in general practice.

Learning activities have been developed to address the learning objectives, with the needs of programme learners at the heart of the design. Participants are registered/ licensed pharmacists and will likely to be juggling the requirements of work at the same time as completing the programme requirements. In response to this, learning activities have been designed for flexible delivery, with one-week residential components at the beginning and end of each semester and the remainder of the course content designed to be delivered on-line.

Problem-based learning (Tais et al., 2014) is used to ensure that students are able to practically apply their learning to real-world scenarios (Lloyd-Jones \& Rushworth, 2000). An example of this is in the medication management UoS where each week pharmacists are provided with a complex medication management case scenario. Pharmacists are required to perform a comprehensive medication review and produce a list of recommendations for the collaborating GP which are then posted on the on-line discussion board for group feedback and comment.

Assessments include online quizzes, participating in online discussion boards and completion of an advanced practice portfolio where learners provide evidence from their clinical placement to confirm that they have capably performed the target professional activities. In addition, performing reflections on practical experiences and OSCES are also included as assessment tasks.

\footnotetext{
* In Australia, pharmacists can undertake postgraduate training to be credentialed as accredited pharmacists able to perform government funded medication review services. Pharmacists completing the Grad. Cert. programme who are currently accredited to provide medication review services, will be enrolled in the advanced medication management unit of study. The medication management subject is aimed at equipping pharmacist with basic medication review skills in comparison to the advanced UoS that is designed to further these skills for pharmacists currently providing medication review services.
} 


\section{Evaluation}

The planned evaluation processes at completion of the pilot in 2020 includes:

- Survey and focus group feedback from both programme participants and academic staff on each unit of study and in regards to the course as a whole. Where possible the focus group will include students with diversity in terms of gender, ethnicity and student performance;

- Analysis of student formative feedback to adjust learning objectives and assessments;

- Survey of participants' employers to determine to what extent the course is fit for purpose; and

- The GP Pharmacist Educational Programme Advisory Committee will be consulted to allow for on-going governance and compliance with University standards.

\section{Implementation}

As course participants will probably be from a variety of pharmacy backgrounds, they are likely to have a wide variety of previous work experiences and educational qualifications. This will require a need for flexibility in the course design to enable the course to be delivered in a learner-centred fashion (Iglar et al., 2013).

Ensuring accessibility is also an important element of successful continuing education design (Farrell et al., 2012). Learners for this course are likely to originate from all states of Australia. Due to the geographical distances between states in Australia, designing the course to provide a combination of short residential components, online tasks and clinical placements in the students' local areas will ensure the course is suitable for a wider range of pharmacist participants.

In order to ensure that graduate outcomes align with the competencies required of GP pharmacists, the Graduate Certificate in Advanced Pharmacy Practice is designed to accommodate the need for adjustment and continuous improvement as the GP pharmacist scope of practice evolves.

\section{Conclusion}

The Graduate Certificate in Advanced Pharmacy Practice is a successful extension of the approach used in the GSH for the development of graduate-entry masters programmes in health disciplines. This evidence-based approach to curriculum development has combined a widely consultative, needs-focussed approach with the best of constructivist methodologies to achieve a set of learning objectives that align with the competencies identified by the representatives of Australian pharmacy schools. It is expected that pharmacists completing the course are equipped with the skills, training and knowledge to provide best-practice general practice pharmacy care to their patients.

\section{Acknowledgements}

The authors thank the Western Sydney Primary Health Network for their contribution to the development of this programme. In particular Dr Kean Seng-Lim and Mr Walter Kmet for their ongoing support and contributions.

\section{Declaration of Interest}

The authors report no conflict of interest. The authors alone are responsible for the content and writing of the article.

\section{References}

Anderson, C., Zhan, K., Boyd, M., \& Mann, C. (2018). The role of pharmacists in general practice: A realist review. Research in Social \& Administrative Pharmacy, 15(4), 338-345. https:// doi.org/10.1016/i.sapharm.2018.06.001

Australian Qualifications Framework Council. (2013). Australian Qualifications Framework, Second Edition (online). Available at: https://www.aqf.edu.au/sites/aqf/files/aqf-2nd-editionjanuary-2013.pdf

Benson, H., Lucas, C., Benrimoj, S.I., \& Williams, K.A. (2019). The development of a role description and competency map for pharmacists in an interprofessional care setting. International Journal of Clinical Pharmacy, 41, 391-407. https://doi.org/ $\underline{10.1007 / s 11096-019-00808-4}$

Benson, H., Lucas, C., Kmet, W., Benrimoj, S.I., \& Williams, K. (2018a). Pharmacists in general practice: a focus on drug-related problems. International Journal of Clinical Pharmacy, 40(3), 566-572. https://doi.org/10.1007/s11096-018-0617-9

Benson, H., Lucas, C., \& Williams, K. (2020). Establishing consensus for general practice pharmacist education: A Delphi study. Currents in Pharmacy Teaching \& Learning, 12(1), 8-13. https://doi.org/10.1016/j.cptl.2019.10.010

Benson, H., Sabater-Hernández, D., Benrimoj, S.I., \& Williams, K. A. (2018b). Piloting the Integration of Non-Dispensing Pharmacists in the Australian General Practice Setting: A Process Evaluation. International Journal of Integrated Care, 18(2), 4. https://doi.org/10.5334/ijic.3293 
Biggs, J.B., \& Tang, C. (2011). Teaching For Quality Learning At University. Maidenhead, United Kingdom: McGraw-Hill Education

Boud, D., \& Falchikov, N. (2006). Aligning assessment with longterm learning. Assessment and Evaluation in Higher Education, 31(4), 399-413. https://doi.org/10.1080/02602930600679050

Bruno, A., Bates, I., Brock, T., \& Anderson, C. (2010). Towards a global competency framework. American Journal of Pharmaceutical Education, 74(3), 56.https://doi.org/10.5688/ai740356

Butterworth, J., Sansom, A., Sims, L., Healey, M., Kingsland, E., \& Campbell, J. (2017). Pharmacists' perceptions of their emerging general practice roles in UK primary care: a qualitative interview study. British Journal of General Practice, 67(662), e650-e658. https://doi.org/10.3399/bjgp17X691733

Cooke, M., Irby, D. M., O'Brien, B.C., \& Shulman, L.S. (2010). Educating Physicians: A Call for Reform of Medical School and Residency. Hoboken, United States: John Wiley \& Sons, Incorporated

Farrell, B., Dolovich, L., Emberley, P., Gagné, M.-A., Jennings, B., Jorgenson, D., et al. (2012). Designing a novel continuing education program for pharmacists: Lessons learned. Canadian Pharmacists Journal / Revue des Pharmaciens du Canada, 145(4), e7-e16. https://doi.org/10.3821/145.4.cpje7

Foot, H., Freeman, C., Hemming, K., Scott, I., Coombes, I.D., Williams, I.D., Cottrell, N. (2017). Reducing Medical Admissions into Hospital through Optimising Medicines (REMAIN HOME) Study: protocol for a stepped-wedge, cluster-randomised trial. BMJ Open, 7(4), e015301.https://doi.org/10.1136/bmjopen2016-015301

Frank, J.R., Snell, L.S., Cate, O.T., Holmboe, E.S., Carraccio, C., Swing, S.R., \& Harris, K.A. (2010). Competency-based medical education: theory to practice. Medical Teacher, 32(8), 638-645. https://doi.org/10.3109/0142159X.2010.501190

Galvao, T.F., Silva, M.T., Neiva, C.S., Ribeiro, L.M., \& Pereira, M.G. (2014) Problem-Based Learning in Pharmaceutical Education: A Systematic Review and Meta-Analysis. The Scientific World Journal, 2014(Art. 578382). http://dx.doi.org/10.1155/2014/578382

Gruppen, L.D., Burkhardt, J.C., Fitzgerald, J.T., Funnell, M., Haftel, H.M., Lypson, M.L., \& Vasquez, J.A. (2016). Competencybased education: programme design and challenges to implementation. Medical Education, 50(5), 532-539. https:// doi.org/10.1111/medu.12977

Hazen, A., de Groot, E., de Gier, H., Damoiseaux, R., Zwart, D., \& Leendertse, A. (2018). Design of a 15-month interprofessional workplace learning program to expand the added value of clinical pharmacists in primary care. Currents in Pharmacy Teaching and Learning, 10(5), 618-626. https://doi.org/10.1016/ j.cptl.2018.01.006

Hazen, A.C.M., de Bont, A.A., Boelman, L., Zwart, D.L.M., de Gier, J.J., de Wit, N.J., \& Bouvy, M.L. (2018). The degree of integration of non-dispensing pharmacists in primary care practice and the impact on health outcomes: A systematic review. Research in Social \& Adminstrative Pharmacy, 14(3), 228-240. https://doi.org/10.1016/i.sapharm.2017.04.014

Ho S, K.D., Lau, C.B., Yeung, M.B., Leung, D.Y., \& Moses. S.C. (2009). An Outcomes-based Approach to Curriculum Development in Pharmacy. American Journal of Pharmaceutical Education, 73(1). https://doi.org/10.5688/aj730114
Iglar, K., Whitehead, C., \& Takahashi, S.G. (2013). Competencybased education in family medicine. Medical Teacher, 35(2), 115-119. https://doi.org/10.3109/0142159X.2012.733837

lobst, W.F., Sherbino, J., Cate, O.T., Richardson, D.L., Dath, D., Swing, S.R., \& Frank, J.R. (2010). Competency-based medical education in postgraduate medical education. Medical Teacher, 32(8), 651-656. https://doi.org/10.3109/0142159X.2010.500709

Katajavuori, N., Salminen, O., Vuorensola, K., Huhtala, H., Vuorela, P., \& Hirvonen, J. (2017). Competence-Based Pharmacy Education in the University of Helsinki. Pharmacy, 5(2), 29. https://doi.org/10.3390/pharmacy5020029

Koster, A., Schalekamp, T., \& Meijerman, I. (2017). Implementation of Competency-Based Pharmacy Education (CBPE). Pharmacy, 5(1), 10. http://dx.doi.org/10.3390/pharmacy $\underline{5010010}$

Lloyd-Jones, G., \& Rushworth, S. (2000). Problem-based Learning in Medicine: A Practical Guide for Students and Teachers. Medical Education, 34(4), 322-323. https://doi.org/10.1046/i. 1365-2923.2000.0597f.x

Lockyer, J., Bursey, F., Richardson, D., Frank, J.R., Snell, L., \& Campbell, C. (2017). Competency-based medical education and continuing professional development: A conceptualization for change. Medical Teacher, 39(6), 617-622. https://doi.org/ 10.1080/0142159X.2017.1315064

McKenna, H, (1994). The Delphi technique: a worthwhile research approach for nursing? Journal of Advanced Nursing, 19, 1221-1225. https://doi.org/10.1111/i.1365-2648.1994.tb01207.x

Moczygemba, L.R., Pierce, A.L., Dang, A., Emberley, P., Czar, M.J., \& Matzke, G.R. (2017). The ADAPT online education program: A tool for practicing pharmacists delivering patientcentered care. Journal of the American Pharmacists Association (2003), 57(5), 601-607. https://doi.org/10.1016/i.japh. $\underline{2017.05 .007}$

Morcke, A.M., Dornan, T., \& Eika, B. (2013). Outcome (competency) based education: an exploration of its origins, theoretical basis, and empirical evidence. Advances in Health Sciences Education: Theory and Practice, 18(4), 851-863. https:// doi.org/10.1007/s10459-012-9405-9

Pharmaceutical Society of Australia. (2016a). General Practice Pharmacist Essential Guide. Pharmaceutical Society of Australia (online). Available at: https://my.psa.org.au/s/article/GeneralPractice-Pharmacist-Essential-Guide

Pharmaceutical Society of Australia. (2016b). NationalCompetency Standards Framework for Pharmacists in Australia 2016 (online). Available at: https://www.psa.org.au/practicesupport-industry/national-competency-standards/

Tan, E.C., Stewart, K., Elliott, R.A., \& George, J. (2014). Pharmacist services provided in general practice clinics: a systematic review and meta-analysis. Research in Social \& Administrative Pharmacy, 10(4), 608-622. https://doi.org/ 10.1016/i.sapharm.2013.08.006

Thangaratinam, S., \& Redman, C.W.E. (2005). The Delphi technique. The Obstetrician and Gynaecologist, 7(2), 120-125. https://doi.org/10.1576/toag.7.2.120.27071 